\title{
The Suggestion of the Reform of the Assistant Nurse System at Dental Field in Korea
}

\author{
Ok-Nyeo Hong \\ Korean Licensed Practical Nurses Association, Seoul, Korea
}

\begin{abstract}
Assistant nurse is the one of the health workforce who work for medical or dental assistant or nurse assistant works at the medical centers, social security centers or community health centers, in order to promoting the health level for the people. The certified numbers of the assistant nurse are about 763 thousands and $28 \%$ of them have been working. Among them, 19,425 have been working in dental fields as 371 for dental hospitals and 19,054 for dental clinics. Assistant nurse can do such roles as dental assisting, assist for dental diagnosis, intra muscular or intra venous injection, assisting for prescription of medication and nurse records, at the dental fields, according to the regulation by the Ministry of Health and Welfare, Korean government. So, the reform of the educational system and the training course for assistant nurse in dental fields should be needed in order to adjust the Korean dental environment, because it has been adapted for the medical oriented system at present in Korea.
\end{abstract}

Keywords: dental assistant, dental workforce

\section{Introduction}

1. The workforce of the assistant nurse at present

Assistant nurse is the one of the health workforce who work for medical or dental assistant or nurse assistant works at the medical centers, social security centers or community health centers, in order to promoting the health level for the people [1].

Assistant nurse system in Korea was established through the regulation for medical assistant law in 1966 and correct it named as an assistant nurse with the medical law in 1987.

\section{Corresponding author Ok-Nyeo Hong}

E-mail: smail427@hanmail.net

(iD) https://orcid.org/0000-0001-7061-5041

Received May 29, 2021, Accepted June 20, 2021
763,127 of assistant nurse have been cerified untill in 2019 and among them, $28 \%$ of them as 213,005 was working at the medical or dental field. $9 \%$ of their workforce of assistant nurses as 19,425 were work at dental field as 371 for dental hospital and 19,425 for dental clinics [2] (Table 1).

It revealed that a little bit increasing tendency of the numbers who worked in dental or oriental clinics and it showed as from 15,191 in the year 2015 to 19,054 in 2019 as $2.5 \%$ of increasement at dental clinics.

It was the similar situations as medical and oriental clinics to increasement of a little numbers of assistant nurses as from 62,737 in 2015 at medical clinics to 75,593 in 2019 as $2.0 \%$ of increasement of the working numbers and from 13,302 in the year 2015 to 21,396 in 2019 as $6.1 \%$ of increasement at oriental clinics. The distribution of their work places in the year 2019 were showed as $16 \%$ for dental clinics, $65 \%$ for medical clinics and $18 \%$ of them for oriental clinics (Table 2).

As the mention about the education and training for assis-

Copyright (C) 2021. Korean Academy of Preventive Dentistry. All rights reserved.

This is an Open Access article distributed under the terms of the Creative Commons Attribution Non-Commercial License (http://creativecommons.org/licenses/ by-nc/4.0) which permits unrestricted non-commercial use, distribution, and reproduction in any medium, provided the original work is properly cited. 
International Journal of Clinical Preventive Dentistry

Table 1. Work places at dental field for assistant nurse in Korea, 2019

(Unit: persons)

\begin{tabular}{ccccc}
\hline \multirow{2}{*}{ Certificated numbers (A) } & Working numbers(B) & \multicolumn{3}{c}{ Dental field } \\
\cline { 3 - 5 } & & Subtotal(C) & D.Hospital(D) & D.Clinics(E) \\
\hline $763,127(100 \%)$ & $213,005(\mathrm{~A} / \mathrm{B})(28 \%)$ & $19,425(\mathrm{~B} / \mathrm{C})(9 \%)$ & 371 (C/D) $(2 \%)$ & $19,054(\mathrm{C} / \mathrm{E})(98 \%)$ \\
\hline
\end{tabular}

Table 2. The distribution of assistant nurse for primary clinics in Korea

(Unit: persons)

\begin{tabular}{|c|c|c|c|c|c|c|}
\hline Working place & 2015 & 2016 & 2017 & 2018 & 2019 & 2015 vs 2019 \\
\hline Total & $91,230(100 \%)$ & $105,194(100 \%)$ & $104,708(100 \%)$ & $107,862(100 \%)$ & $116,043(100 \%)$ & $24,813(27 \%)$ \\
\hline Dental Clinic & $15,191(17 \%)$ & $18,052(17 \%)$ & 17,785 (17\%) & $17,569(16 \%)$ & $19,054(16 \%)$ & $3,863(25 \%)$ \\
\hline Medical Clinic & $62,737(69 \%)$ & $70,692(67 \%)$ & $70,720(68 \%)$ & $74,146(69 \%)$ & $75,593(65 \%)$ & $12,856(20 \%)$ \\
\hline Oriental Clinic & $13,302(14 \%)$ & $16,450(16 \%)$ & $16,203(15 \%)$ & $16,147(15 \%)$ & $21,396(18 \%)$ & $8,094(61 \%)$ \\
\hline
\end{tabular}

Table 3. The training numbers for the assistant nurse for recent 5 years (Unit: persons)

\begin{tabular}{ccccc}
\hline Year & $\begin{array}{c}\text { Applied } \\
\text { numbers }\end{array}$ & $\begin{array}{c}\text { Tested } \\
\text { numbers }\end{array}$ & $\begin{array}{c}\text { Passed } \\
\text { numbers }\end{array}$ & Pass rate \\
\hline Average for 5 & 48,473 & 45,823 & 34,322 & $74.9 \%$ \\
2015 & 53,449 & 50,273 & 31,303 & $62.2 \%$ \\
2016 & 55,250 & 52,035 & 37,169 & $71.4 \%$ \\
2017 & 46,010 & 43,320 & 34,033 & $78.6 \%$ \\
2018 & 45,145 & 42,889 & 35,229 & $82.1 \%$ \\
2019 & 42,513 & 40,598 & 33,874 & $83.4 \%$ \\
\hline
\end{tabular}

tant nurse, 34,322 were passed for the certification test for assistant nurse from 50,273 appliances, in the year 2015, 37,169 from 52,035 in 2016, 34,033 from 43,320 in 2017, 35,229 from 42,889 in 2018 and 34,322 from 45,823 in 2019 as average $74.8 \%$ of pass rate for 5 years as 34,322 of passed persons from 45,823 of appliances for total numbers of 5 years (Table 3 ).

\section{Educational system for assistant nurse}

More than 1,520 hours of training course as 740 hours for lecture and 780 hours for practical training were required at the nurse training private institute and written test would be done from the Korean Medical Workforce Examination Institute. The final passed one can be certified the assistant nurse certification from the Minister of Health and Welfare in Korean government [3].

The suggested curriculum and the regulation about the assistant nurse from the National Occupation Evaluation Institute would be shown in Table 4.

\section{The role of the assistant nurse}

Assistant nurse is a workforce for assisting the nurses at the hospital levels but can take roles with the nurses without the helps of nurses at the clinic levels as medical, dental or oriental
Table 4. The guide-line for the educational evaluation by National Occupation Evaluation Institute

\begin{tabular}{clcr}
\hline Curriculum & \multicolumn{1}{c}{ Unit } & Lecture & Practice \\
\hline \multirow{2}{*}{ Basic nursing } & Nursing care & 25 & \\
& Basic nursing & 80 & 36 \\
& Adult nursing & 70 & 3 \\
& Maternal nursing & 50 & 1 \\
& Child nursing & 50 & 1 \\
& Senior nursing & 30 & 1 \\
& Emergency nursing & 30 & 8 \\
& Basic anatomy and physiology & 80 & \\
& Basic pharmacology & 20 & \\
& Basic nutrition & 20 & \\
& Basic dental science & 25 & \\
Nursing health & Basic oriental medicine & 20 & \\
science & Health education & 15 & \\
& Health administration & 20 & \\
& Evironmental health & 30 & \\
Public health & Industrial health & 20 & \\
science & Disease control program & 30 & \\
& Population and delivery & 10 & \\
& Maternal health & 10 & \\
& Community health & 25 & \\
& Medical law & 30 & \\
\hline
\end{tabular}

clinics, under the control of the doctors, dentists and oriental doctors, even though they are not the main workforce for medical field, according to the medical law in Korea. The main roles of assistant nurse are such as assisting for diagnosis, injection shotting, medical or dental treatment assisting, and nurse chart recording, according to the interpretation of the medical law from the ministryof Health and Welfare in Korea.

As the mention about the dental hygienists, as one of the dental workforce, they can do apply the orthodontic wire, scaling, fluoride topical application, intral-oral X-ray taking, temporary filling, temporary setting stain removal, impression 
taking and the others as prevention works at the teeth and around the teeth tissue, according to the para-medical law.

\section{Body}

\section{Unadaptable system for dental cares on the assistant nurse system}

The most of the activities and education contents for assistant nurse has been forcused for medical cares and not for dental cares, in spite of $9 \&$ of total assistant nurses as 19,425 of assistant nurses have worked at the dental hospitals and dental clinics. So assistant nurse is hard for recognized as a professional workforce under this system.

Only 25 hours were distributed among 740 hours of lecture time in assistant education system and the most of the students were practical training for 780 hours, at the medical hospitals and not for dental hospitals. Moreover, only one or two questions for dental field, among 100 questions for test, can be suggested on the national board examination. So it would be estimated that the present assistant nurse education system is hard for adjusted for the workforce training on dental field.

Table 5. The evaluation about the dental field part contents from the curriculum for assistant nurse education

(Unit: \%)

\begin{tabular}{llrrr}
\hline & Item & \multicolumn{3}{c}{ Defficient } \\
\hline Educational level & High school & 66.8 & 22.0 & 11.2 \\
& College & 71.3 & 22.1 & 6.6 \\
& University & 72.0 & 20.0 & 8.0 \\
Career & Post graduate school & 100.0 & 0.0 & 0.0 \\
& Under 5 years & 73.4 & 15.2 & 11.4 \\
& 5-10 years & 69.5 & 25.3 & 5.3 \\
Total & 10-15 years & 61.1 & 30.0 & 8.9 \\
& Over 15 years & 70.1 & 18.1 & 11.9 \\
& & 68.5 & 21.8 & 9.8 \\
\hline
\end{tabular}

Table 6. The survey for the need about the continuing education

(Unit: \%)

\begin{tabular}{llrrr}
\hline & Item & No need & Medium & Need \\
\hline Educational level & High school & 16.1 & 24.0 & 59.9 \\
& College & 14.0 & 32.2 & 53.7 \\
& University & 23.5 & 11.8 & 64.7 \\
\multirow{4}{*}{ Career } & Post graduate school & 0.0 & 0.0 & 100.0 \\
& Under 5 years & 21.5 & 26.6 & 51.9 \\
& 5-10 years & 14.7 & 28.4 & 56.8 \\
Total & 10-15 years & 15.6 & 20.0 & 64.4 \\
& Over 15 years & 15.3 & 24.4 & 60.2 \\
& & 16.5 & 24.8 & 58.7 \\
\hline
\end{tabular}

\section{Survey for the reform of the education system}

Dasan Economic Research Institute has announced that only $9.3 \%$ of assistant nurses answered "enough" $21.3 \%$ of them answered as "moderate" but $68.3 \%$ answered as "defficient" for the dental field contents in the assistant nurse education curriculum through the questionnaire survey for assistant nurses. from the trust research for the Ministry of Health and Welfare in Korean government (Table 5).

About the continuing education, $16.5 \%$ of them answered as "No need" but $24.6 \%$ of them answered as "Medium" and $53.7 \%$ of them answered as "Need", in order to promotion of their roles continuously. But majority as $76.7 \%$ of them answered that they have not received the continuing education or training from their present work place (Table 6).

It revealed that there was much deficient for dental contents for the assistant nurse education, according to the questionnaire survey from Dasan Economic Research Institute. And needed so much for training about the dental field contents, but there has not enough opportunities to receive the dental education at the present work places (Table 7).

\section{Illegal roles for dental hygienist and assistant nurse}

It revealed that there have been worked the dental hygienists and assistant nurse together at $53.6 \%$ of the dental clinics

Table 7. Receiving the eligible education for the assistant nurse from the present work place

(Unit: \%)

\begin{tabular}{llcc}
\hline & Item & Not supplied & Supplied \\
\hline Educational level & High school & 73.9 & 26.1 \\
& College & 62.8 & 37.2 \\
& University & 70.6 & 29.4 \\
\multirow{4}{*}{ Career } & Post graduate school & 0.0 & 100.0 \\
& Under 5 years & 70.3 & 29.7 \\
& 5-10 Years & 75.6 & 24.4 \\
\multirow{4}{*}{ Total } & 10-15 Years & 68.4 & 31.6 \\
& Over 15 Years & 67.0 & 33.0 \\
& & 76.7 & 23.3 \\
\hline
\end{tabular}

Table 8. Workforces for dental hygienists and assistant nurse at the dental clinics

(Unit: \%)

\begin{tabular}{lccc}
\hline \multicolumn{1}{c}{ Item } & $\begin{array}{c}\text { Dental } \\
\text { hygienist }\end{array}$ & $\begin{array}{c}\text { Assistant } \\
\text { nurse }\end{array}$ & total \\
\hline D.H. and A.N. together & 52.0 & 55.3 & 53.6 \\
Only dental hygienist & 48.0 & - & 24.5 \\
Only assistant nurse & - & 44.7 & 21.9 \\
Total & 100.0 & 100.0 & 100.0 \\
\hline
\end{tabular}


and only dental hygienists worked at $24.5 \%$ of the dental clinics and only assistant nurse worked at $21.9 \%$ of dental clinics, according to the survey from Dasan Economy Research Institute (Table 8).

The relative weight for invasion to the others roles between the dental hygienist and assistant nurse at the dental clinics were revealed as $40.0 \%$ of dental hygienists have done the assistant nurses roles and answered that $35.4 \%$ of them though their works as assistant nurse's work. Otherwise, $64.5 \%$ of the assistant nurse at dental clinics have thought their works as the dental hygienist's works and $64.8 \%$ of their works might be a dental hygienist's works (Table 9).

It has been known as different the roles of the dental hygienist and assistant nurse at the dental clinis. But there was not so remarkable boarders between their roles of works at the dental clinics at present situation, according to the analysis from the Dasan Economic Research Institute. They sometimes invasion to other's roles by situations and sometimes do the other's works, in spite of the illegal from the medical law and

Table 9. Invasion rate for each role at dental clinics between the dental hygienist and assistant nurse

(Unit: \%)

\begin{tabular}{ccccc}
\hline \multicolumn{2}{c}{ Dental hygienist } & & \multicolumn{2}{c}{ Assistant nurse } \\
\cline { 1 - 1 } $\begin{array}{c}\text { Role for } \\
\text { assistant nurse }\end{array}$ & $\begin{array}{c}\text { Weight among } \\
\text { their own works }\end{array}$ & & $\begin{array}{c}\text { Roles for } \\
\text { dental hygienist }\end{array}$ & $\begin{array}{c}\text { Weight among } \\
\text { their own works }\end{array}$ \\
\hline 40.0 & 35.4 & 64.5 & 64.8 \\
\hline
\end{tabular}

para-medical law. So it needed to re-establish the role of both workforces or reform of thr medical and paramedical law in the future (Table 10).

\section{Conclusion}

It would be considered the following answers to solve the above problems.

\section{Establishment of dental assistant system}

Dental assistant should be belong to one of the assistant nurse system like the special assistant nurse establishing with the consideration of the home visiting assistant nurse after finishing with 700 hours training or specialized social workers and physical trainer who are certified with their abilities from the ministry of Health and Welfare in Korean government, in order to recognized with the special assistant workforce in the dental field.

It was suggested to be a dental assistants by applying from the assistant nurses, as one of the certifying the dental assistants from the assistant nurses. This idea should be needed to reform of the medical laws in order to make the basic back grounds. Dental assistant should be grown up for dental works mainly, on the contrary as the assistant nurse at present should be work for medical works.

Under this plan for the suggestion, some careered assistant nurse can be applied to be a dental assistant, after finishing the dental education which has suggested curriculum from the

Table 10. The performance rate for the roles at the dental clinics

(Unit: \%)

\begin{tabular}{|c|c|c|c|c|c|c|}
\hline \multirow{2}{*}{ Item of the work } & \multicolumn{3}{|c|}{ Dental hgienist } & \multicolumn{3}{|c|}{ Assistant nurse } \\
\hline & Always do & Often do & Not do & Always do & Often do & Not do \\
\hline Eliminate calculus & 80.6 & 12.7 & 6.8 & 46.0 & 18.8 & 35.1 \\
\hline Fluoride topical application & 48.7 & 26.9 & 24.5 & 30.7 & 17.5 & 51.8 \\
\hline Temporary filling & 60.3 & 21.2 & 18.6 & 38.6 & 18.9 & 42.5 \\
\hline Removal of temporary crown & 63.9 & 20.1 & 16.0 & 46.4 & 19.2 & 34.4 \\
\hline Deposit removal & 60.0 & 21.2 & 18.8 & 45.1 & 20.0 & 34.9 \\
\hline Impression taking & 75.1 & 13.5 & 11.4 & 53.1 & 22.0 & 24.9 \\
\hline Orthodontic wire bending/setting/removal & 35.7 & 16.4 & 47.9 & 24.3 & 10.9 & 64.9 \\
\hline Prevention at teeth/oral cavity & 76.5 & 16.3 & 7.2 & 55.0 & 22.9 & 22.2 \\
\hline Intra oral X-ray taking & 81.4 & 13.1 & 5.5 & 59.2 & 18.6 & 22.2 \\
\hline Injection & 7.0 & 9.6 & 83.4 & 28.0 & 3.6 & 68.4 \\
\hline Phamacological work & 6.3 & 8.5 & 85.2 & 24.9 & 3.2 & 71.9 \\
\hline Vital sign check & 15.3 & 30.3 & 54.4 & 37.9 & 14.1 & 48.1 \\
\hline Assist for diagnosis/blood & 6.5 & 13.3 & 80.2 & 29.9 & 7.3 & 62.8 \\
\hline Assist for treatment, washing, disinfection & 73.5 & 17.3 & 9.2 & 82.8 & 9.1 & 8.2 \\
\hline Operation preparation, assisting for anesthesia & 69.4 & 17.5 & 13.1 & 79.8 & 10.9 & 9.3 \\
\hline Assisting for operation & 68.8 & 16.4 & 14.8 & 75.7 & 12.0 & 12.2 \\
\hline $\begin{array}{l}\text { Pdst operative treatment/instruction, antiseptic } \\
\text { treatment for dressing, suture removal }\end{array}$ & 53.3 & 29.3 & 17.5 & 48.2 & 20.6 & 31.2 \\
\hline
\end{tabular}


ministry of Health and Welfare, and then, would be referd the certification. In case of considering the dental assistant system from the education, it should consider for 1,520 hours of the dental training, as the same training hours with the assistant nurse education.

\section{Preparation of the curriculum for dental assstant and national board exam}

In case of educating the assistant nurse forcusing as dental works to utilize at the dental field, assistant nurses worked at the dental field with several careers, would be certified after educated certain periods prepared with the standard curriculum and practical traing at the dental clinics or dental hospitals, without consideration of establishing the dental assistant system.

It should be needed to reform the national board examination in consideration with the assistant nurse manpower according to the level of the medical organization, and the activities or the roles for them, for the relative weight of the quantity of the questions It was suggested as 200 questions from 100 at present for the assistant nurse national board examination, in order to increase the numbers of the questions for the dental field.

\section{Re adjustment of the roles for dental assistant and dental hygienist}

It can be hard to keep the regulation about each role for dental workforces as dental hygienist and assistant nurse at dental clinic under the present dental situations, without employing the both workforces as dental hygienist and assistant nurse together at all dental clinics. But there are some difficulties to do that because of the business or management difficulties.
It can be suggested with the ideal idea to establish their roles independently in consideration of the co-operation with each works, because it is the defferent workforce between the dental hygienist and assistant nurse at the dental clinic. So it was suggested to reform the system with the idea for performing the works for both of them.

It means that some works which could be done by dental hygienist only can be extended the role for permitting all or some part to dental assistant who had got the certification by training and on the contrary, some works for permitted only for assistant nurse at present, would be permitted to dental hygienist, withcase by case, in consideration of dental situations at present in Korea.

\section{Conflict of Interest}

No potential conflict of interest relevant to this article was reported.

\section{ORCID}

Ok-Nyeo Hong, https://orcid.org/0000-0001-7061-5041

\section{References}

1. Dasan Economy Research Institute, Ministry of Health and Welfare, A study for the demend and supply for the dental assisting workforce 2018.11.30.

2. Korean Assistant Nurse Association, The development of the standard curriculrum for the assistant nurse education. 2019.12

3. Korean Health and Social Research Institute, A study on the program development of the works for assistant nurse 2020.10.3 